\title{
Increased Expression of Pyloric ER $\beta$ Is Associated With Diabetic Gastroparesis in Streptozotocin-Induced Male Diabetic Rats
}

\author{
Stephen Crimmins ${ }^{\mathrm{a}, \mathrm{d}}$, e, Rebecca Smiley ${ }^{\mathrm{a}, \mathrm{d}}$, Kerry Preston ${ }^{\mathrm{a}}$, Amy Yau ${ }^{\mathrm{b}}$, Richard Mccallumc, \\ Mohammed Showkat Alia
}

\begin{abstract}
Background: Gastroparesis is a significant co-morbidity affecting up to $50 \%$ of patients with diabetes and is disproportionately found in women. Prior studies have suggested that loss of interstitial cells of Cajal, hyperglycemia, and nitric oxide dysfunction are potential causes of gastroparesis. Since diabetic gastroparesis affects more women than men, we performed an exploratory study with a diabetic rat model to determine if sex hormone signaling is altered in those where gastroparesis develops.
\end{abstract}

Methods: We injected male rats with streptozotocin (STZ) to model type I diabetes, as confirmed by blood glucose levels. Gastroparesis was determined by acetaminophen gavage and serum acetaminophen levels. Rats were grouped based on acetaminophen and blood glucose data: diabetic (DM), diabetic and gastroparetic (DM + GP), and control (CM). Serum levels of testosterone, estrogen, and insulin were determined as well as aromatase expression in pyloric tissue and serum. Androgen receptor and estrogen receptor $\alpha(\mathrm{ER} \alpha)$ and $\beta(\mathrm{ER} \beta)$ were also measured in the pylorus.

Results: Compared to CM, estrogen increased and testosterone decreased in both DM and DM + GP rats. Sex hormone levels were not different between DM and DM + GP. Serum aromatase was increased in DM and DM + GP rats; however, pyloric tissue levels were not significantly different from controls. ER $\alpha$ was unchanged and androgen receptor decreased in DM and DM + GP. ER $\beta$ was increased only in $\mathrm{DM}+\mathrm{GP}$ animals.

Conclusion: Our study implicates increased pyloric ER $\beta$ in the de-

Manuscript accepted for publication April 15, 2016

aDepartment of Clinical Investigation, William Beaumont Army Medical Center, 5005 N. Piedras Street, El Paso, TX 79920-5001, USA

${ }^{b}$ Internal Medicine Clinic, San Antonio Military Medical Center, 3551 Roger Brooke Dr., San Antonio, TX 78219, USA

'Department of Internal Medicine, Texas Tech Health Science Center Paul L. Foster School of Medicine, 4800 Alberta Ave, El Paso, TX 79905-2709, USA ${ }^{\mathrm{d}}$ These authors contributed equally to first authorship of this manuscript.

${ }^{e}$ Corresponding Author: Stephen Crimmins, Department of Clinical Investigation, William Beaumont Army Medical Center, 5005 N. Piedras Street, El Paso, TX 79920, USA. Email: stephen.1.crimmins.mil@mail.mil

doi: http://dx.doi.org/10.14740/gr701w velopment of gastroparesis in STZ-induced male diabetic rats. Increased serum aromatase is likely responsible for altered sex hormone levels. Our study supports the implication of sex hormone signaling in diabetic development and demonstrates a potential unique role for pyloric ER $\beta$ in male diabetic gastroparesis.

Keywords: Estrogen; Gastroparesis; Diabetes

\section{Introduction}

Gastroparesis is a growing public health issue. Gastroparesis is a condition defined by the delayed emptying of stomach contents into the duodenum. Symptoms of gastroparesis include early satiety, abdominal distension, nausea, vomiting, abdominal pain, and poor glycemic control [1]. Most cases of gastroparesis are idiopathic, but can be co-morbid with such diseases as diabetes, anorexia nervosa, bulimia, liver or renal failure, mitochondrial disorders, gastric dysrhythmias, visceral myopathies, and pancreatitis. In diabetic patients, there is a higher incidence rate in female compared to male patients. Both human studies and animal models indicate that insulin, nitric oxide, ICC, hyperglycemia, and hormones like incretin, CCK, PYY, and ghrelin may all contribute to and/or be correlated with gastroparesis [1-5]. Thus, the evidence suggests that there are many possible systems that can contribute to gastroparesis.

These hormone and neuropeptides are innate to the normal pathophysiology of digestion. The stomach can be split into three separate anatomic regions: the fundus, the corpus, and the antrum; and two superimposed functional regions: the gastric reservoir and the gastric pump. The pylorus is a sphincter that acts as a gatekeeper between the antrum and the duodenum. The gastric reservoir and the gastric pump overlap in the medial portion of the corpus. Stomach motility begins with food stimulus in the oropharynx which signals the vagal center of the brain. The vagal center sends inhibitory biochemical signals to the fundus which causes the gastric reservoir to relax and accept digestant. These inhibitory signals are nitric oxide, pituitary adenylate cyclase activating peptide, vasoactive intestinal peptide, and adenosine triphosphate. The food nutrients and further distension of the reservoir result in more signaling to the vagal center. As a consequence, the corpus 
reservoir relaxes thus further increasing the reservoir volume available to accept food [6].

Ingested materials are transported through the stomach with the tonic contraction of the fundus in conjunction with the peristaltic waves in the gastric pump towards the antrum. The peristaltic waves are controlled by a network of interstitial cells of Cajal (ICC) which provide pacesetting potentials. With the release of acetylcholine from nerves and an influx of calcium at the maximum of the pacesetting potential, the peristaltic contraction occurs and the digestate flows into the antrum. The ingested bolus flows into the duodenum when the peristaltic contraction hits the middle of the antrum and the pylorus is signaled to open. Once in the duodenum, nutrients and other biochemical signals provide negative feedback to the vagal center which then causes re-relaxation of the fundus. Normal gastric motility requires an integrated and coordinated interplay between the sympathetic, parasympathetic, and enteric nervous systems; gastrointestinal (GI) smooth muscle cells; endocrine signaling; and nutrient feedback. A malfunction at any level has the potential to alter gastric function and emptying [6].

A number of human and animal studies point to the intersection of sex hormone signaling, macronutrient feedback, and hepatic glucogenesis in the development of gastroparesis. Given the increased prevalence among women, sex hormone signaling, then, may be involved in diabetic gastroparesis. In TIDM, where insulin production is ablated, increased hepatic gluconeogenesis and decreased insulin-dependent glucose uptake by adipocytes and skeletal myocytes result in a hyperglycemic state. Hyperglycemia then slows gastric emptying, as has been observed in both normal and insulin-dependent diabetes mellitus patients, to inhibit postprandial hyperglycemia [5].

Estrogen (E2) signaling, while not directly implicated in gastric emptying, is known to be a modulator of glucose homeostasis $[7,8]$. In a streptozotocin (STZ) model of TIDM, estrogen therapy in male rats had a significant effect on improving blood glucose control and liver pathology. The effects were suspected to be from residual pancreatic beta-cell proliferation and increased expression of insulin receptors in the liver [9]. Hormone replacement therapy studies in women also provide evidence that estrogen and progestin treatments are protective against type II diabetes in postmenopausal women [10]. In addition, E2 infusion was found to reverse STZ-induced type I diabetes in male rodents [7]. In a case study involving a male with aromatase deficiency, blood work demonstrated both a hyperinsulinemic and hyperglycemic state that was modestly improved with estrogen therapy [11]. As can be seen in these examples, estrogen plays an important role in the glycemic state and by extension, possibly the gastric emptying rate.

Due to the connection of estrogen to blood glucose, and of blood glucose to gastric emptying, we performed an exploratory analysis on sex hormone signaling in an STZ-induced model of male diabetic gastroparesis. Because hyperglycemia is attenuated by estrogen in both males and females, we evaluated estrogen and its closely related hormones and receptors. These include testosterone, aromatase (which converts testosterone to estradiol), estrogen receptors alpha $(\mathrm{ER} \alpha)$ and beta $(\mathrm{ER} \beta)$, and the androgen receptor (AR).

\section{Materials and Methods}

\section{Materials}

Charles River (San Diego, CA) supplied virgin male SpragueDawley rats. Sigma-Aldrich Inc. (St. Louis, MO) supplied all reagent grade chemicals. Anti-mouse ER $\alpha$ and anti-mouse ER $\beta$ were purchased from EMD Millipore Inc. (Bellerica, MA), anti-rabbit AR was from Santa Cruz Biotechnol. (Dallas, TX), and anti-mouse actin antibody was from Sigma-Aldrich Inc.

\section{Animals}

Ninety-seven virgin male Sprague-Dawley rats at 12 weeks old (200 - $250 \mathrm{~g})$ were given standard rat chow and water ad libitum. After an overnight fast, we induced type I diabetes by a single IP injection of $55 \mathrm{mg} / \mathrm{kg}$ of STZ (Sigma-Aldrich Inc.) in $100 \mathrm{mM}$ citrate buffer $(\mathrm{pH} 4.5)$; an equivalent volume of $100 \mathrm{mM}$ citrate buffer ( $\mathrm{pH} 4.5$ ) was used in control animals as a sham injection. Seventy-seven rats were injected with STZ and 20 rats were used as control. Of all STZ-injected rats, 22 developed diabetes and 26 developed diabetic gastroparesis. Twenty-nine STZ-injected rats died, did not develop diabetes, or underwent diabetes reversal. Five control rats were chosen randomly for the control group. The five animals with the highest fasting blood glucose levels and the five animals with the slowest measurement of gastric emptying were chosen for the diabetic and diabetic gastroparesis groups, respectively. Blood glucose was measured after overnight fasting every third day for 16 weeks using an Accu-check blood glucose meter (Roche Diagnostics, Basel, Switzerland). A blood glucose level of $>$ $300 \mathrm{mg} / \mathrm{dL}$ was considered diabetic. At 12 weeks, we subjected rats to a gastric emptying assay. This test allowed us to split the rats into the following study groups: male rats: 1) control citrate buffer injection (CM); 2) diabetic after STZ treatment (DM); and 3) diabetic and gastroparetic after STZ treatment $(\mathrm{DM}+\mathrm{GP})$. At the end of week 16, serum and gastric tissues were collected from the animals for biochemical assays.

\section{Measurement of liquid gastric emptying}

After $24 \mathrm{~h}$ of fasting, $0.3 \mathrm{~mL}$ of blood was collected from the tail vein to establish baseline acetaminophen levels. The rats were then gavaged with $50 \mathrm{mg}$ of acetaminophen dissolved in a liquid meal $(3.0 \mathrm{~mL})$. Four hours after feeding, another $0.3 \mathrm{~mL}$ of blood was collected to measure post-feeding acetaminophen levels [12]. The difference between pre- and postfeeding acetaminophen levels was used as the index of gastric emptying and expressed as $\mu \mathrm{g} / \mathrm{mL}$ of acetaminophen per $\mathrm{mL}$ of blood. Serum acetaminophen ELISA kits were purchased from Immunanalysis Corporation (Pomona, CA). Based on our current and previous observations, and from the observations of others, $2-4 \mu \mathrm{g} / \mathrm{mL}$ of acetaminophen was used as the cutoff for group designations $[13,14]$. Since liquids emptied the stomach at an exponential rate, it would be expected that normal gut 
motility would cause the clearance of acetaminophen rapidly resulting in lower serum values. In a gastroparetic state, the emptying of the gut was slowed; as a result, higher serum values would be obtained thus indicating gastroparesis.

\section{Measurement of estrogen, testosterone, insulin and aro- matase}

Blood samples collected immediately prior to euthanasia were used to measure serum estrogen and testosterone levels by ELISA (Cayman Chemical, Ann Arbor, MI and Alpco Diagnostic, Salem, NH, respectively). Insulin was also measured using an ELISA kit from Cayman Chemical. An aromatase kit purchased from Cloud-Clone Corp. (Houston, TX) was used to determine aromatase levels in serum and extracted pyloric tissue. We followed the manufacturer's instructions for all ELISA kits.

\section{Western blotting for measurement of $\operatorname{ER} \alpha$ and $\operatorname{ER} \beta$ and AR}

Pyloric tissues were stored at $-80{ }^{\circ} \mathrm{C}$ until use. Pyloric tissue was homogenized in tissue extraction buffer (Thermofisher Scientific, Waltham, MA). The tissue lysates were then centrifuged for $15 \mathrm{~min}$ at $15,000 \times \mathrm{g}$ and the protein concentration of the supernatant was determined using a protein assay kit (Thermofisher Scientific). Equal amounts of tissue proteins were then separated by $10 \%$ SDS-PAGE gel and transferred onto a nitrocellulose membrane. After blocking the membranes with $5 \%$ non-fat milk diluted in buffer $(10 \mathrm{mM}$ Tris- $\mathrm{HCl}, 100 \mathrm{mM} \mathrm{NaCl}$ and $0.1 \%$ Tween 20 ) for $3 \mathrm{~h}$ at room temperature, specific proteins were probed with primary antibodies (anti-mouse $\mathrm{ER} \alpha \mathrm{mAb}$ (1:1,000 dilution), anti-rabbit $\operatorname{AR~pAb~(1:100~dilution)~or~anti-mouse~} \operatorname{ER} \beta$ mAb (1:1,000 dilution)) for $4 \mathrm{~h}$ at room temperature. Actin antibody was used as a control and run on a separate gel from the target proteins due to image signal interference; IR-dye conjugated secondary antibodies (anti-mouse IRDye800 or anti-rabbit IRDye800) at a dilution of 1:20,000 were then added and incubated for $1 \mathrm{~h}$ at room temperature.

\section{Statistical analysis}

We reported statistics as the mean \pm standard deviation for the response variables with five rats for each group. To test the mean differences among the three groups, the one-way analysis of variance (ANOVA) was employed with original units or logarithmic transformation. With significant ANOVA, the least significant difference (LSD) post hoc procedure was used to check for mean differences. We set the level of significance at 0.05 .

\section{Results and Discussion}

In the current study, we used an STZ model to induce type I
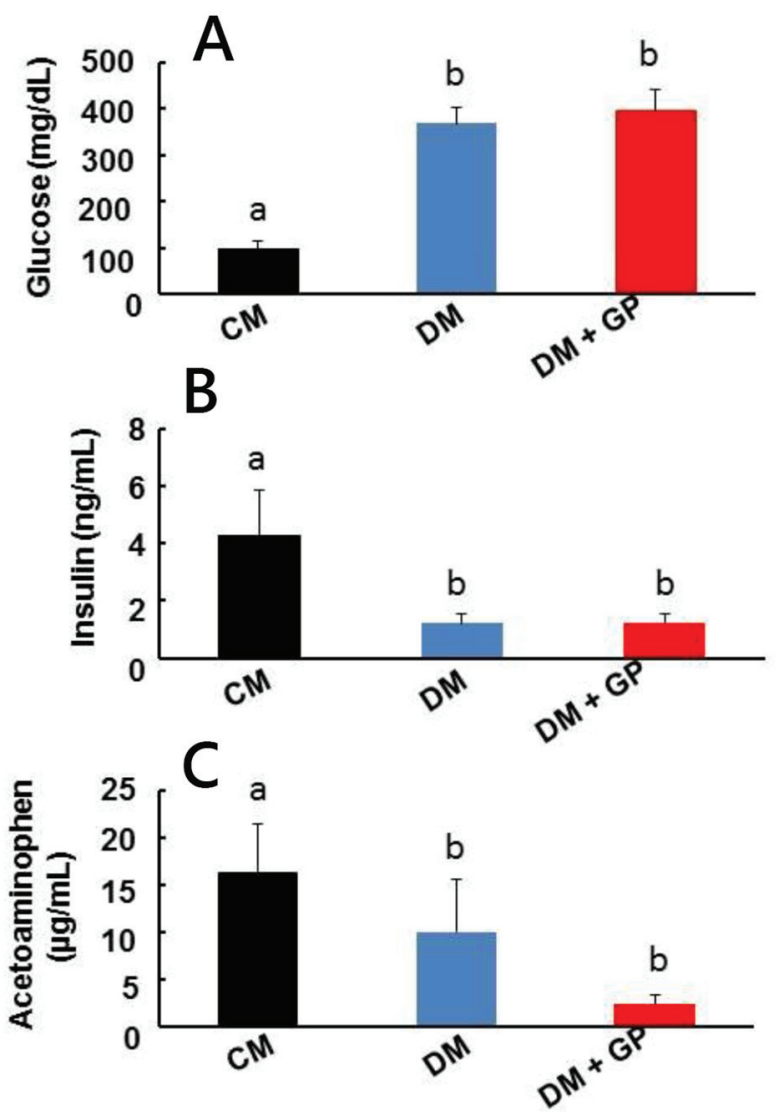

Figure 1. Pathophysiology of healthy, diabetic, and diabetic gastroparetic male rats. CM: age-matched control male rats injected with the same volume of citrate buffer without STZ. DM: male rats developed diabetes following STZ administration. DM + GP: male rats injected with STZ that developed diabetes and gastroparesis. The difference in values is marked as "a" and "b". Five rats were included in each group. (A) DM + GP rats and DM rats had no significant difference in glucose levels ( $396.2 \pm 45.9$ vs. $367.8 \pm 33.2 \mathrm{mg} / \mathrm{dL}$ ). CM: $4.27 \pm 1.56$. (B) Insulin levels: serum insulin level measured in CM, DM, and DM + GP rats. Both DM and DM + GP rats had reduced insulin levels $(1.20 \pm 0.34 \mathrm{ng} /$ $\mathrm{mL}$ and $1.21 \pm 0.31 \mathrm{ng} / \mathrm{mL}$; overall ANOVA, $P=0.0001$, respectively) compared to control rats $(4.27 \pm 1.56 \mathrm{ng} / \mathrm{mL})$. Each column represents the mean \pm standard deviation of five rats per group. $P \square 0.05$. (C) The difference between fasting and post-feeding acetaminophen levels is used as the index of gastric emptying. Slower gastric emptying was only detected in DM + GP rats and not in CM and DM $(16.16 \pm 5.25 \mu \mathrm{g} /$ $\mathrm{mL}$ vs. $2.22 \pm 1.05$ and $9.96 \pm 5.58$; overall ANOVA, $P=0.0001$ )

diabetes in a cohort of male rats and tested them for gastroparesis after 12 weeks [13]. Ninety-seven virgin male SpragueDawley rats at 12 weeks old $(200-250 \mathrm{~g})$ were used for this study. Seventy-seven rats were injected with STZ and 20 rats were used as control. Of all STZ-injected rats, 22 developed diabetes and 26 developed diabetic gastroparesis. Twenty-nine STZ-injected rats died, did not develop diabetes, or underwent diabetes reversal. Five control rats were chosen randomly for the control group. The five animals with the highest fasting blood glucose levels and the five animals with the slowest measurement of gastric emptying were chosen for the diabetic and diabetic gastroparesis groups, respectively. We found that 

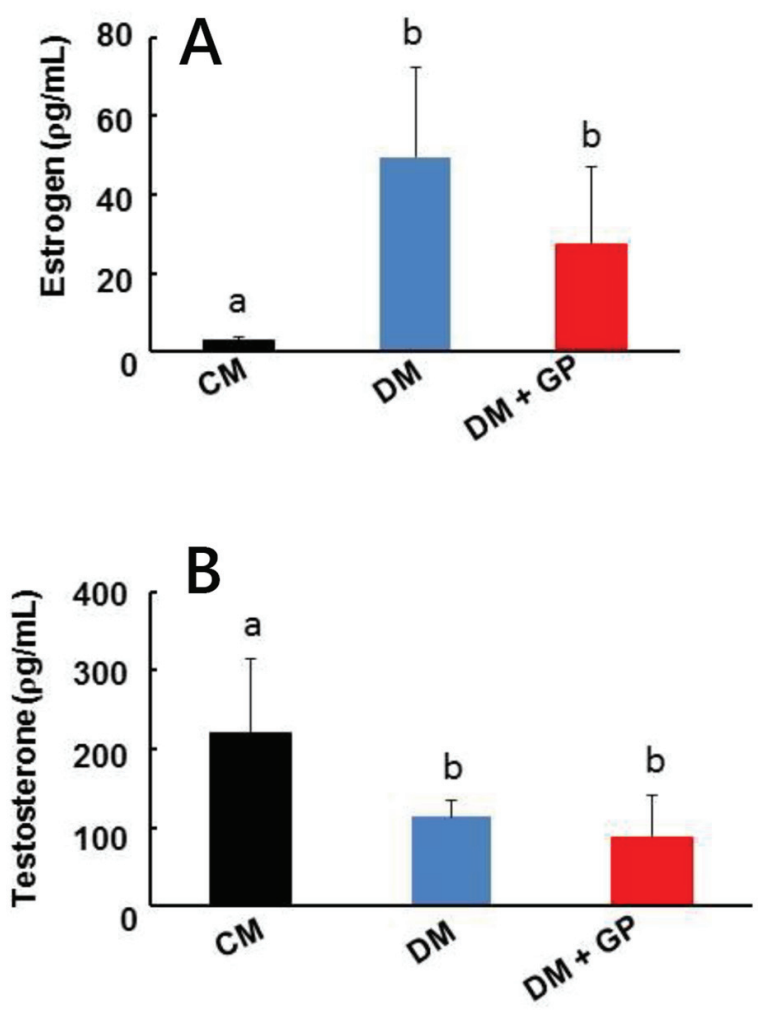

Figure 2. Serum sex hormone level in healthy, diabetic, and diabetes gastroparetic rats. Five rats were included in each group. (A) Estrogen: increases in estrogen $\left(E_{2}\right)$ were observed in $D M$ and $D M+G P$ rats (DM: $49.50 \pm 22.77 \mathrm{pg} / \mathrm{mL}$; DM + GP: $27.28 \pm 19.59 \mathrm{\rho g} / \mathrm{mL}$, respectively; overall ANOVA, $\mathrm{P}=0.0004)$ compared to $\mathrm{CM}$ rats $(2.94 \pm 0.71$ $\rho g / m L)$. (B) Testosterone: testosterone concentrations were decreased in the DM $(113.87 \pm 21.80 \rho \mathrm{g} / \mathrm{mL})$ and DM + GP rats $(88.51 \pm 52.69 \mathrm{\rho g} /$ $\mathrm{mL}$; overall ANOVA, $\mathrm{P}=0.012$ ) and groups compared to the $\mathrm{CM}$ group $(219.82 \pm 95.47 \mathrm{\rho g} / \mathrm{mL})$. Each column represents the mean \pm standard deviation of five rats per group. The difference in values is marked as "a" and "b".

the incidence of diabetes without gastroparesis (DM rats) was approximately $29 \%$. An additional $34 \%$ of rats developed both diabetes and gastroparesis $(\mathrm{DM}+\mathrm{GP})$ and were treated as a separate group. Control rats (CM) injected with citrate buffer alone did not develop either diabetes or gastroparesis. As expected, DM rats and DM + GP rats had similar glucose levels which were above the cutoff of $300 \mathrm{mg} / \mathrm{dL}(367.8 \pm 33.2 \mathrm{mg} /$ dL vs. $396.2 \pm 45.9$, Fig. 1 A). CM rats had $4.27 \pm 1.56 \mathrm{mg} /$ dL. Figure $1 \mathrm{C}$ shows the acetaminophen levels and establishes their group designation of DM or DM + GP.

It is has been demonstrated that insulin is important for normal gut motility. For example, Russo et al showed that insulin-induced hypoglycemia accelerates gastric emptying of solids and liquids in type I diabetes [15]. However, it is presumed that the normalization of gut motility is due to the induction of a hypoglycemic state and macro-nutrient feedback on the gut, rather than a direct action of insulin, as was suggested by Ahmed and Hassanein [9]. As expected, the induction of a hypoinsulinemic state did induce a hyperglycemic state (Fig. 1B). Insulin levels were significantly decreased in DM (1.20 \pm
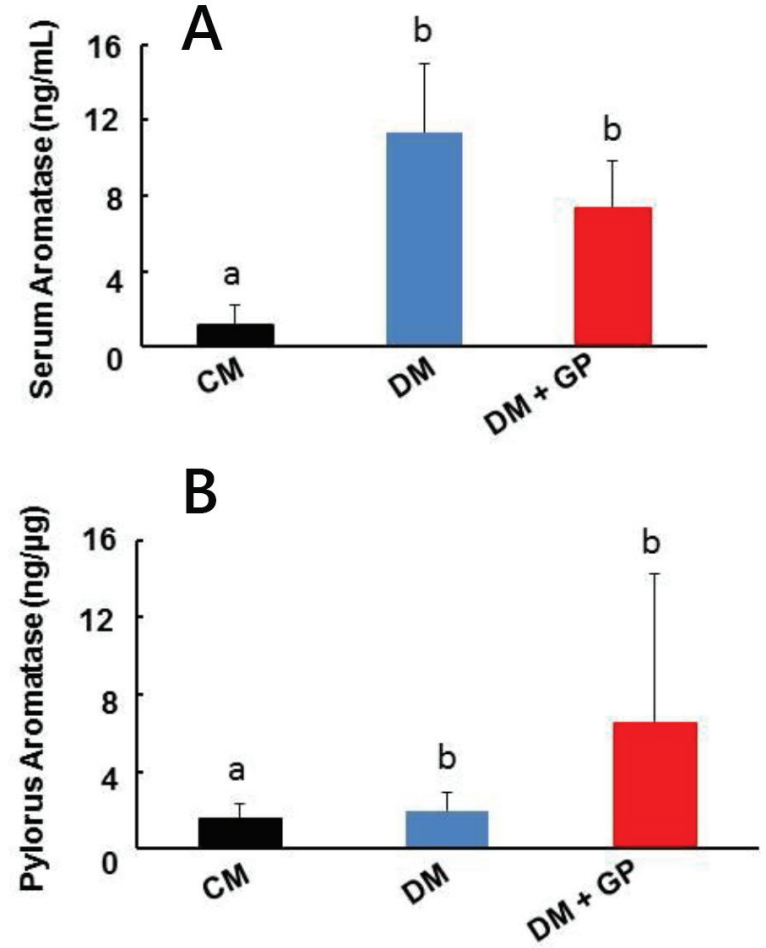

Figure 3. Aromatase levels in control, diabetic, diabetes and gastroparetic rats. Five rats were included in each group. (A) Serum levels of aromatase from DM $(11.37 \pm 3.65 \mathrm{ng} / \mathrm{mL})$ and $\mathrm{DM}+\mathrm{GP}(7.37 \pm 2.44$ $\mathrm{ng} / \mathrm{mL}$; overall ANOVA, $\mathrm{P}=0.003$ ) rats were increased compared to levels in CM rats $(1.12 \pm 1.11 \mathrm{ng} / \mathrm{mL})$. Each column represents the mean \pm standard deviation of five rats per group. (B) Pyloric tissue level of aromatase: compared with CM rats $(1.59 \pm 0.78 \mathrm{ng} / \mathrm{mL})$, there was no change in tissue aromatase level in both DM $(2.00 \pm 0.91 \mathrm{ng} / \mathrm{mL})$ and DM + GP rats $(6.54 \pm 7.74 \mathrm{ng} / \mathrm{mL}$; overall ANOVA, $P=0.144)$. Each column represents the mean \pm standard deviation of five rats per group. The difference in values is marked as "a" and "b".

$0.34 \mathrm{ng} / \mathrm{mL})$ and $\mathrm{DM}+\mathrm{GP}(1.21 \pm 0.31 \mathrm{ng} / \mathrm{mL})$ rats compared to the control CM rats $(4.27 \pm 1.56 \mathrm{ng} / \mathrm{mL}$; overall ANOVA, $\mathrm{P}=0.0001$, and both significant with LSD pairwise comparisons at $\alpha=0.05$ ). Based on Ahmed and Hassanein's study, we expected that a hyperglycemic state would result in a slowed gastric emptying time [9]. In contrast, we found that all diabetic animals had both increased blood glucose and decreased insulin levels, but only a subset developed gastroparesis. Our data suggest that hyperglycemia alone is not responsible for the development of gastroparesis in an STZ model of type I diabetes in male rats thus strengthening the results from previous studies [16]. At 33\%, The STZ model does somewhat mimic the incidence of diabetic gastroparesis in humans at about $50 \%$ of the total number of diabetic patients. Since gastroparesis is not $100 \%$ associated with diabetes, this suggests a complex regulatory mechanism whereby hyperglycemia may only play a partial role.

Figure 2A demonstrates increased estrogen levels in DM $(49.50 \pm 22.77 \mathrm{pg} / \mathrm{mL})$ and $\mathrm{DM}+\mathrm{GP}$ rats $(\mathrm{DM}: 27.28 \pm 19.59$ $\mathrm{pg} / \mathrm{mL})$ when compared to control CM rats $(2.94 \pm 0.71 \mathrm{pg} /$ $\mathrm{mL}$; overall ANOVA, $\mathrm{P}=0.0004$, and both significant with 


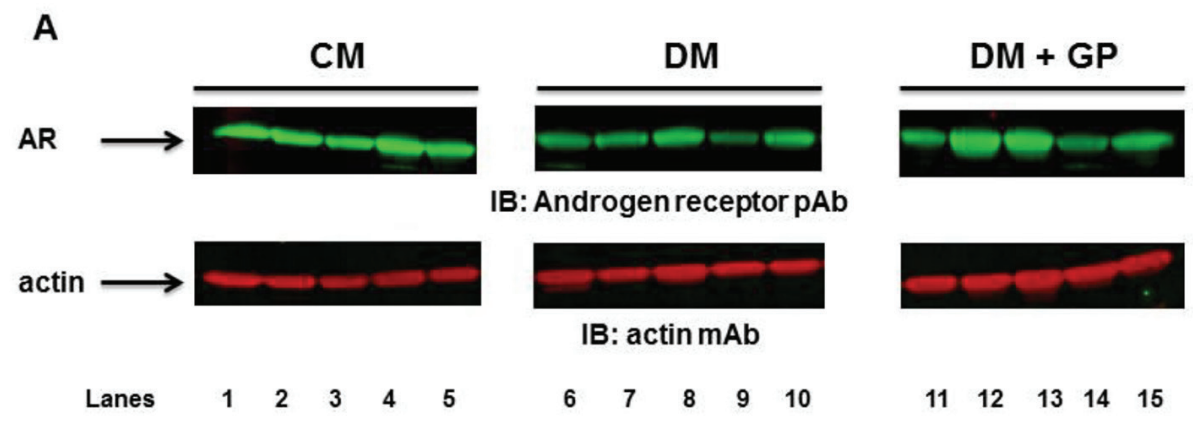

B

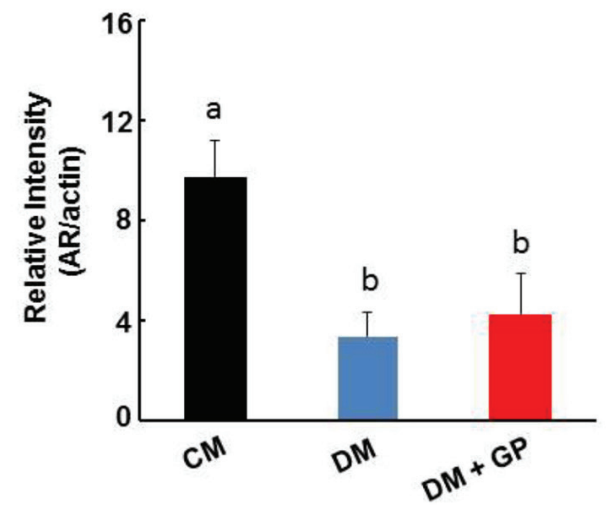

Figure 4. Expression of AR in the gastric pylorus. Five rats were included in each group. (A) Representative immunoblot showing the level of AR (upper panel) and actin (lower panel). (B) The level of AR was normalized to that of actin by densitometric analysis and expressed as arbitrary units. The relative intensity of the AR protein was shown to be decreased in both $D M(3.37 \pm 0.95)$ and $\mathrm{DM}+\mathrm{GP}(4.2 \pm 1.66)$ compared to CM $(9.67 \pm 1.52$; overall ANOVA, $\mathrm{P}=0.00002 ; \mathrm{P} \square 0.05)$. Data are expressed as the mean \pm standard deviation of five animals per group. The difference in values is marked as "a" and "b".

LSD pairwise comparisons at $\alpha=0.05)$. However, there was no statistical significance between DM and DM + GP estrogen levels, suggesting no defined connection between increased plasma estradiol levels in DM rats leading to gastroparesis development.

We examined testosterone signaling because testosterone is a precursor to estradiol in men. As shown in Figure 2B, we found that testosterone levels were decreased in the DM + GP $(88.51 \pm 52.69 \mathrm{pg} / \mathrm{mL})$ and DM $(113.87 \pm 21.80 \mathrm{pg} / \mathrm{mL})$ group compared to the CM group $(219.82 \pm 95.47 \mathrm{pg} / \mathrm{mL}$; overall ANOVA, $\mathrm{P}=0.012$, and both significant with LSD pairwise comparisons at $\alpha=0.05$ ). However, there was again no statistical significance between DM and DM + GP suggesting that decreased testosterone levels are not directly responsible for gastroparesis development.

We wanted to confirm that the increase in estrogen and decrease in testosterone were due to an increase in aromatase, an enzyme that converts testosterone to estrogen. Serum aromatase was significantly increased in DM $(11.37 \pm 3.65 \mathrm{ng} /$ $\mathrm{mL})$ and $\mathrm{DM}+\mathrm{GP}(7.37 \pm 2.44 \mathrm{ng} / \mathrm{mL})$ rats compared to $\mathrm{CM}$ controls (1.12 $\pm 1.11 \mathrm{ng} / \mathrm{mL}$; overall ANOVA, $\mathrm{P}=0.0003$, and both significant with LSD pairwise comparisons at $\alpha=0.05$; Fig. 3A). Our data suggest that serum aromatase is responsible for the increased estrogen and possibly the decreased testosterone levels in DM and DM + GP rats, but does not play a role in the development of gastroparesis since there was no significant difference between DM and DM + GP rats.

Although we did not see significant changes in circulatory levels of estrogen, testosterone, or aromatase between DM and $\mathrm{DM}+\mathrm{GP}$ rats, we decided to examine the pylorus to determine if there was a smaller, localized effect of sex hormone signaling on gastric emptying. Pyloric tissue aromatase levels were similar in all groups, including CM rats, suggesting that localized estrogen production by pyloric aromatase does not contribute to gastroparesis in our model (Fig. 3B, DM + GP: $6.54 \pm 7.74 \mathrm{ng} / \mu \mathrm{g}$; DM: $2.00 \pm 0.91 \mathrm{ng} / \mu \mathrm{g}$ vs. CM: $1.59 \pm 0.78$ $\mathrm{ng} / \mu \mathrm{g}, \mathrm{P}=0.144)$.

Since total values of sex hormones or aromatase could not be directly linked to the development of gastroparesis, we examined localized expression of ER and AR in the pylorus. Changes in localized expression of receptors could alter downstream pathways directly at the pylorus, bypassing the vagal center, and play a role in the development of diabetic gastroparesis via tissue specific mechanisms, possibly through NO signaling. To test the hypothesis that different expression patterns of ER and AR in the pylorus may contribute to the etiology of gastroparesis, we measured pyloric levels of ER $\alpha, E R \beta$, and $\mathrm{AR}$ in the CM, DM, and DM + GP groups.

As for AR, the relative intensity of the protein was shown to be significantly decreased in both DM $(3.37 \pm 0.95)$ and DM 
A

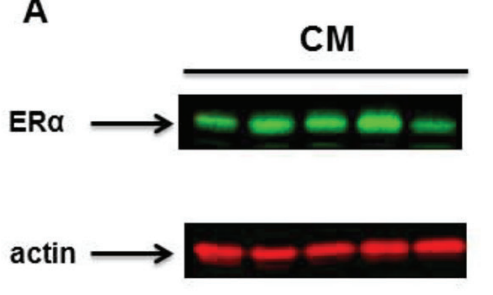

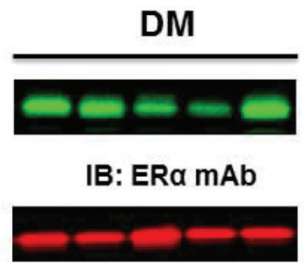

IB: actin mAb

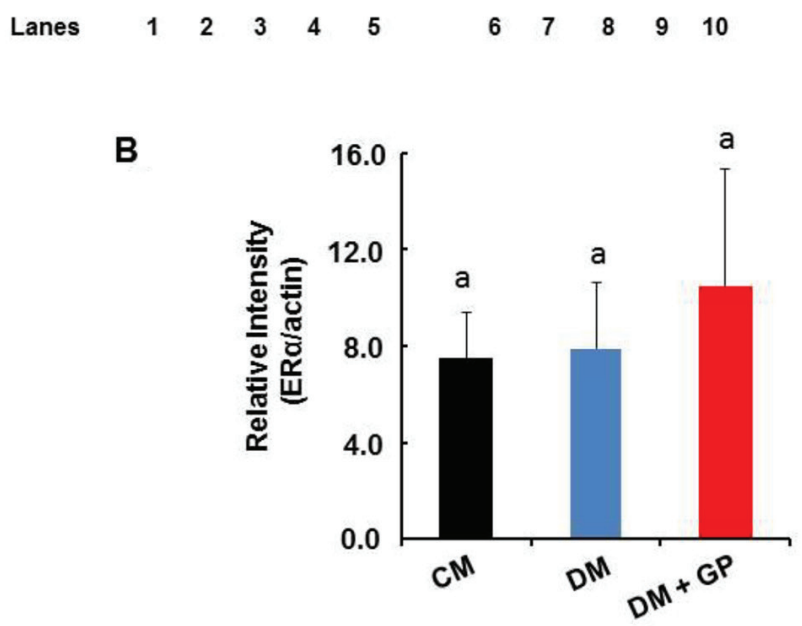

Figure 5. Expression of ERa in the gastric pylorus. Five rats were included in each group. (A) Representative immunoblot showing the level of ERa (upper panel) and actin (lower panel) in the pylorus. (B) The level of ERa was normalized to that of actin by densitometric analysis and expressed as arbitrary units. The values are expressed as arbitrary units (DM + GP rats $8.90 \pm 6.61$ vs. DM $5.82 \pm 3.1$ and CM $5.68 \pm 2.16$; overall ANOVA, $P=0.45$ ). Data are expressed as the mean \pm standard deviation of five animals per group. The difference in values is marked as "a" and "b".

+ GP (4.2 \pm 1.66$)$ compared to CM rats $(9.67 \pm 1.52$; overall ANOVA, $\mathrm{P}=0.00002$, and both significant with LSD pairwise comparisons at $\alpha=0.05$; Fig. 4). The AR data indicate that localized increase of the receptor at the pylorus may contribute to overall diabetic pathology but not to diabetic gastroparesis.

Our results demonstrate that there is no difference in the level of ER $\alpha$ among DM (5.82 \pm 3.1$), \mathrm{DM}+\mathrm{GP}(8.90 \pm 6.61)$, and $\mathrm{CM}(5.69 \pm 2.16)$, indicating that this receptor does not contribute to the development of diabetic gastroparesis (Fig. $50.45)$.

Interestingly, ER $\beta$ protein in the pylorus significantly increased in DM + GP but not in DM rats when compared to CM rats (Fig. 6A). Figure 6B shows the quantitation of the protein band for ER $\beta$ as normalized with actin by densitometric analysis and expressed as arbitrary units (DM + GP rats $5.49 \pm 2.16$ vs. DM $3.25 \pm 2.77$ and CM $29 \pm 0.91$; overall ANOVA, P $=0.028$, and both significant with LSD pairwise comparisons at $\alpha=0.05$ ). The specificity of increased ER $\beta$ in the pylorus indicates a role for this receptor in diabetic gastroparesis in a male STZ model of type I diabetes. To our knowledge, this is the first reported finding that demonstrates localized pylorus pathology for ER $\beta$, thus proposing a potential role for this receptor in STZ-induced type I diabetic gastroparesis.

From these results, we conclude that ER $\beta$ expression and the downstream activation of associated genes might be one factor in the complex development of gastroparesis in a subset of DM rats. Due to the complexity of gut motility signaling, many more studies are needed to tease out the role of ER $\beta$ in gastroparesis. However, as one possibility, it is known that estrogen can induce nitric oxide mediated smooth muscle vascular dilation. ER $\beta$ knockout mice lost the vasodilation response to estrogen, demonstrating a requirement for this receptor in smooth muscle cell tone [17]. It is conceivable that ER $\beta$ also plays a role in the smooth muscle tone of the pylorus. When the expression of ER $\beta$ is dysregulated, estrogen signaling may be lost in the normal pathophysiology of pyloric sphincter relaxation, conceivably slowing gastric emptying and contributing to the onset of gastroparesis.

The current work is limited by the fact that we did not examine factors that may cause the upregulation of ER $\beta$. Further work should include pylorus biopsy to determine if the upregulation of ER $\beta$ is present prior to the STZ treatment. The study should be replicated in female rats to determine if the phenomenon is universal between the sexes. The in vivo use of the ER $\beta$ selective agonist (WAY200070) could be used to determine if the receptor is the causative agent for gastroparesis in STZ-induced diabetes [18]. In addition, analyzing the loss and downstream effects other peptides synthesized by pancreatic $\beta$ cells may yield insights on ER $\beta$. Despite these limitations, our study finds that the male STZ-induced type I diabetic rat is characterized by abnormal sex hormone signaling that is specific for ER $\beta$. Our study also shows that the ER $\beta$ receptor 


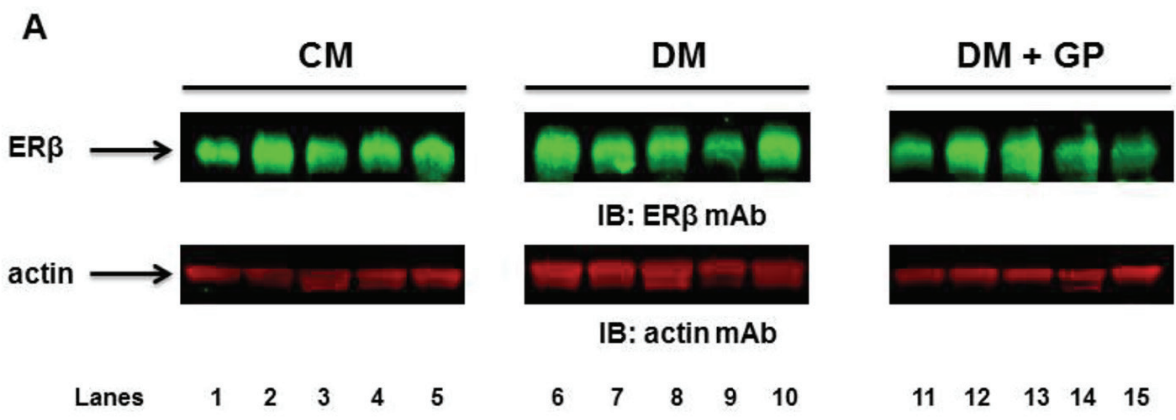

B

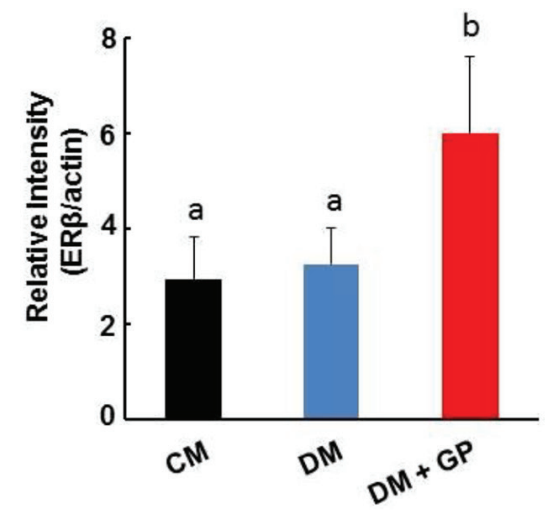

Figure 6. Expression of ER $\beta$ in the gastric pylorus. Five rats were included in each group. (A) Representative immunoblot showing the level of ERß (upper panel) and actin (lower panel) in the pylorus. (B) The level of ER $\beta$ was normalized to that of actin by densitometric analysis and expressed as arbitrary units. The values are expressed as arbitrary units (DM + GP rats $5.49 \pm 2.16$ vs. DM $3.25 \pm 2.77$ and CM $2.9 \pm 0.91$; overall ANOVA, $P=0.028$ ). Data are expressed as the mean \pm standard deviation of five animals per group. The difference in values ise marked as "a" and "b".

is specifically upregulated in the pylorus of DM + GP rats, suggesting a pathophysiology of diabetic gastroparesis. Based on these findings, it is conceivable that restoring ER $\beta$ receptor levels to their physiological levels may provide protection from the development of gastroparesis in male rats.

\section{Financial Disclosures}

All authors do not have any financial arrangement with companies whose products are used in this manuscript or with a company making a competing product.

\section{Disclaimer}

The views expressed in this document are those of the authors and do not reflect the official policy of William Beaumont Army Medical Center, the Department of the Army, or the United States Government.

\section{References}

1. Abrahamsson H. Gastrointestinal motility disorders in patients with diabetes mellitus. J Intern Med.
1995;237(4):403-409.

2. Parkman HP, Camilleri M, Farrugia G, McCallum RW, Bharucha AE, Mayer EA, Tack JF, et al. Gastroparesis and functional dyspepsia: excerpts from the AGA/ANMS meeting. Neurogastroenterol Motil. 2010;22(2):113-133.

3. Prevost G, Ducrotte P, Cailleux A, Khalfi K, Basuyau JP, Lefebvre H, Kuhn JM. Glucose-induced incretin hormone release and insulin sensitivity are impaired in patients with idiopathic gastroparesis: results from a pilot descriptive study. Neurogastroenterol Motil. 2013;25(8):694699.

4. Eliasson B, Bjornsson E, Urbanavicius V, Andersson H, Fowelin J, Attvall S, Abrahamsson H, et al. Hyperinsulinaemia impairs gastrointestinal motility and slows carbohydrate absorption. Diabetologia. 1995;38(1):79-85.

5. Schvarcz E, Palmer M, Aman J, Horowitz M, Stridsberg M, Berne C. Physiological hyperglycemia slows gastric emptying in normal subjects and patients with insulin-dependent diabetes mellitus. Gastroenterology. 1997;113(1):60-66.

6. Ehrlein HJ, Schemann M. Gastrointestinal Motility. http://humanbiology.wzw.tum.de/motvid01/tutorial.pdf, 2016.

7. Louet JF, LeMay C, Mauvais-Jarvis F. Antidiabetic actions of estrogen: insight from human and genetic mouse models. Curr Atheroscler Rep. 2004;6(3):180-185. 
8. Faulds M, Dahlman-Wright K. Estrogen Receptors in Glucose Homeostasis. Update on Mechanisms of Hormone Action - Focus on Metabolism Growth and Reproduction. 2011:15. http://cdn.intechopen.com/pdfswm/22058.pdf. Accessed 2016.

9. Ahmed MA, Hassanein KM. Effects of estrogen on hyperglycemia and liver dysfunction in diabetic male rats. Int J Physiol Pathophysiol Pharmacol. 2012;4(3):156166.

10. Margolis KL, Bonds DE, Rodabough RJ, Tinker L, Phillips LS, Allen C, Bassford T, et al. Effect of oestrogen plus progestin on the incidence of diabetes in postmenopausal women: results from the Women's Health Initiative Hormone Trial. Diabetologia. 2004;47(7):1175-1187.

11. Herrmann BL, Saller B, Janssen OE, Gocke P, Bockisch A, Sperling H, Mann K, et al. Impact of estrogen replacement therapy in a male with congenital aromatase deficiency caused by a novel mutation in the CYP19 gene. J Clin Endocrinol Metab. 2002;87(12):5476-5484.

12. Porsgaard T, Straarup EM, Hoy CE. Gastric emptying in rats following administration of a range of different fats measured as acetaminophen concentration in plasma. Ann Nutr Metab. 2003;47(3-4):132-138.

13. Showkat Ali M, Tiscareno-Grejada I, Locovei S, Smiley R, Collins T, Sarosiek J, McCallum R. Gender and estra- diol as major factors in the expression and dimerization of nNOSalpha in rats with experimental diabetic gastroparesis. Dig Dis Sci. 2012;57(11):2814-2825.

14. Srinivas NR. Acetaminophen absorption kinetics in altered gastric emptying: establishing a relevant pharmacokinetic surrogate using published data. J Pain Palliat Care Pharmacother. 2015;29(2):115-119.

15. Russo A, Stevens JE, Chen R, Gentilcore D, Burnet R, Horowitz M, Jones KL. Insulin-induced hypoglycemia accelerates gastric emptying of solids and liquids in long-standing type 1 diabetes. J Clin Endocrinol Metab. 2005;90(8):4489-4495.

16. Woerle HJ, Albrecht M, Linke R, Zschau S, Neumann C, Nicolaus M, Gerich JE, et al. Impaired hyperglycemiainduced delay in gastric emptying in patients with type 1 diabetes deficient for islet amyloid polypeptide. Diabetes Care. 2008;31(12):2325-2331.

17. Guo X, Razandi M, Pedram A, Kassab G, Levin ER. Estrogen induces vascular wall dilation: mediation through kinase signaling to nitric oxide and estrogen receptors alpha and beta. J Biol Chem. 2005;280(20):19704-19710.

18. Alonso-Magdalena P, Ropero AB, Garcia-Arevalo M, Soriano S, Quesada I, Muhammed SJ, Salehi A, et al. Antidiabetic actions of an estrogen receptor beta selective agonist. Diabetes. 2013;62(6):2015-2025. 